\title{
escuela, en Berna
}

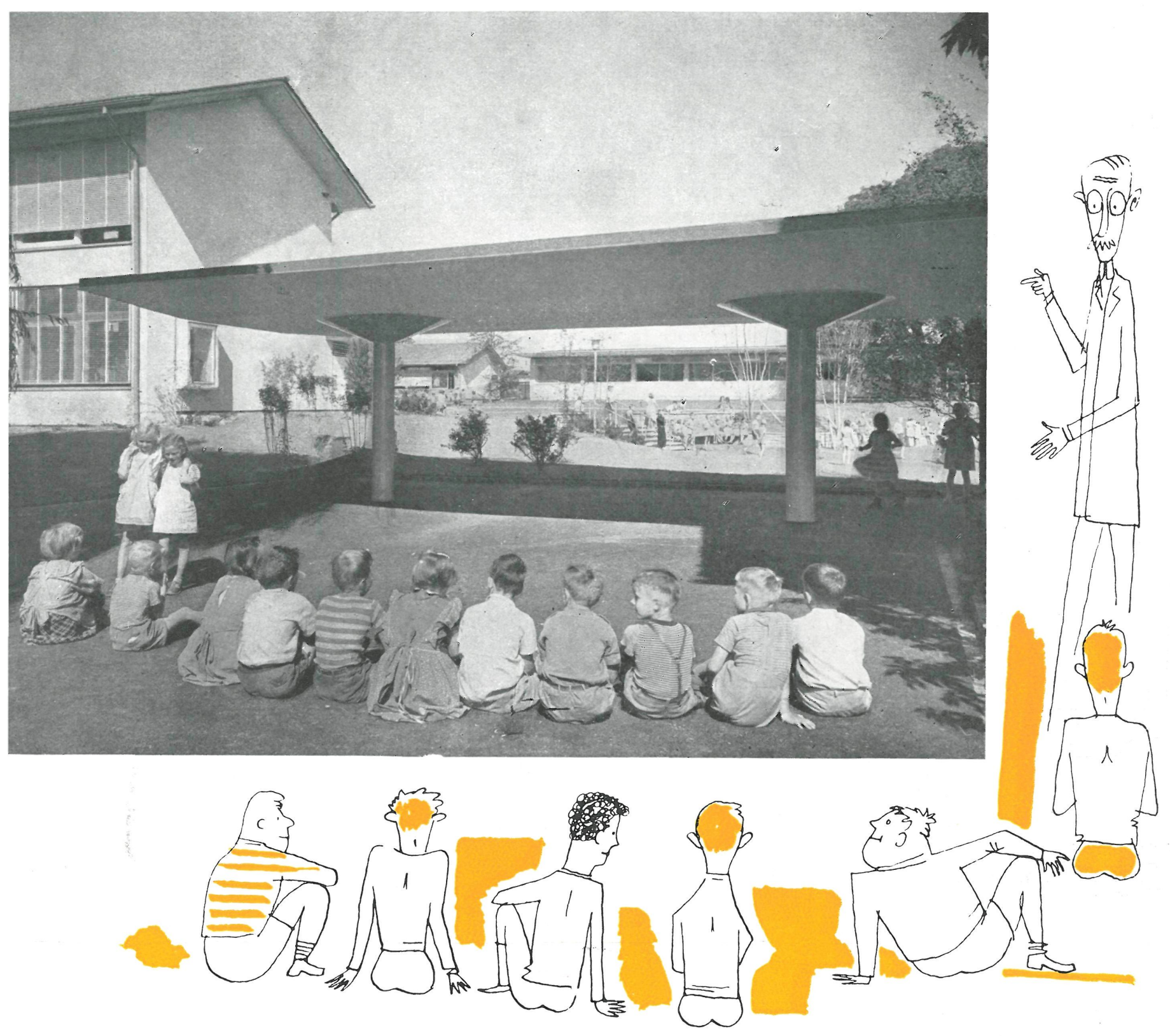

HANS y GRET REINHARD, arquifectos

La escuela Steigerhubel, situada entre Bümpliz y Berna, ha sido construída para satisfacer la necesidad escolar de aquella comarca, ante el aumento progresivo de alumnos. Junto a los edificios que albergan las clases, se ha construído: un gimnasio, un edificio de recepción, una guardería, una iglesia y un edificio central. Desde este último edificio se suministra la calefacción a todo el conjunto.

Es la nota más destacada de esta obra la sustitución del tipo de escuela a base de pasillos por la de tipo pabellón, puesto que es más útil y aprovechable en la enseñanza primaria y proporciona más superficie libre para la distribución de jardines y zonas de recreo. 


\section{situación}

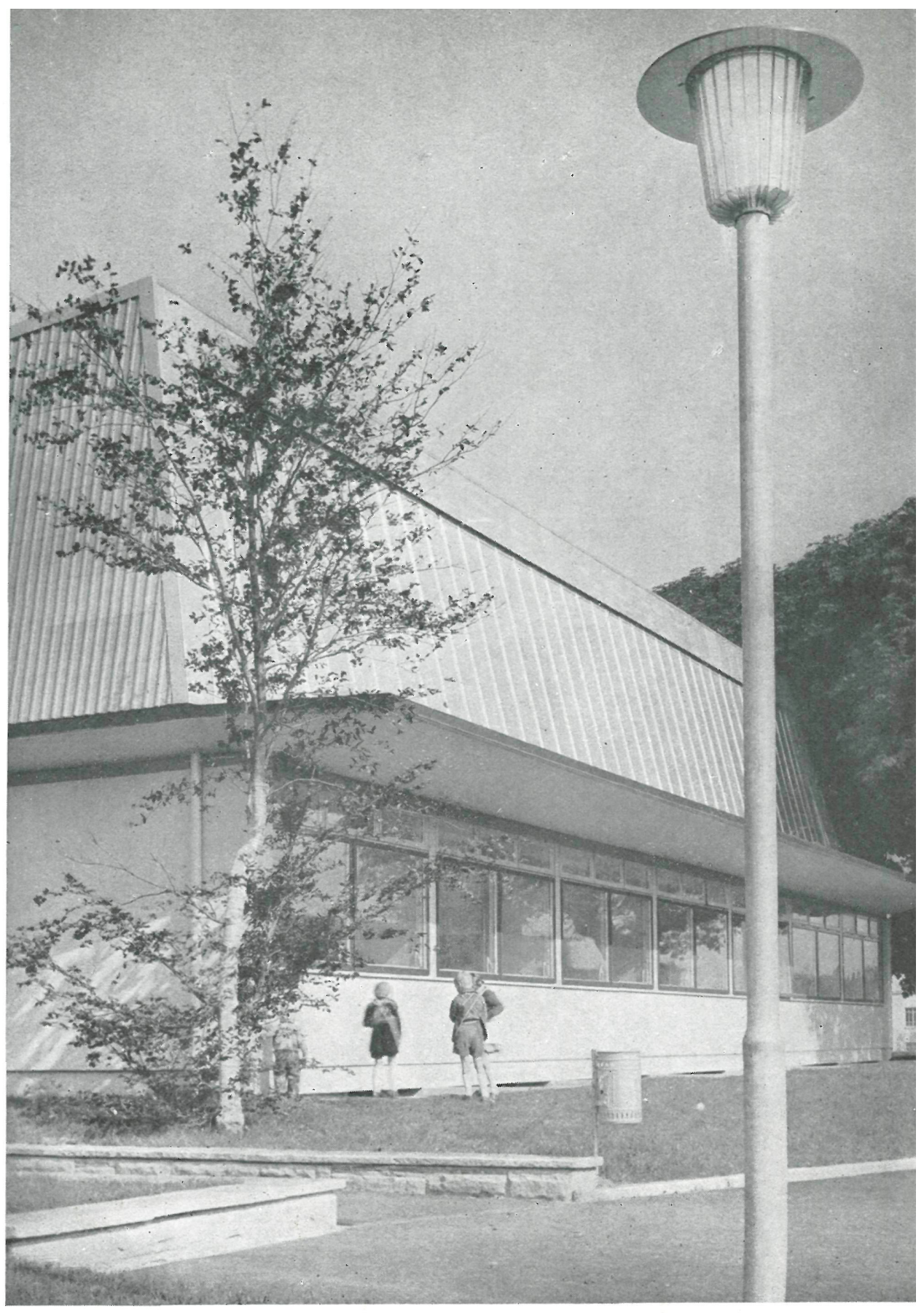

1. Aula primaria.-2. Gimnasio.-3. Guardería.-4. Enseñanza media.-5. Sala conferencias.-6. Iglesia.-7. Jardín infancia.8. Recreo.-9. Patio.-10. Campo verde de juego.-11. Quemadero municipal.-12. Cam-
po público juego.

Ya en la primera década del año 1930, arquitectos como Gisel, Kräher, Bosshart..., en Europa, y Roth en América ensayaron este tipo de edificación escolar. La gran ventaja de la escuela pabellón es la de su fácil adaptación a las diferentes situaciones, tanto en relación a la forma de las parcelas como a las más variadas topografías. Los estudios y experiencias anteriores han demostrado que el mejor tipo de pabellón escuela es el que tiene la caja de escalera central y la iluminación por ambos lados, con unidad de clase a cada lado de la escalera. El centro del pabellón está ocupado no sólo por la escalera de enlace vertical, sino por todas las habitaciones auxiliares y vestíbulos de espera, resueltos sin saliente alguno sobre las fachadas, por crear las plantas en $\mathrm{T}$ o L zonas de sombra que afectan a las superficies de iluminación, con gran perjuicio para las clases, ya que se rompe la uniformidad en la luz de las mismas. 

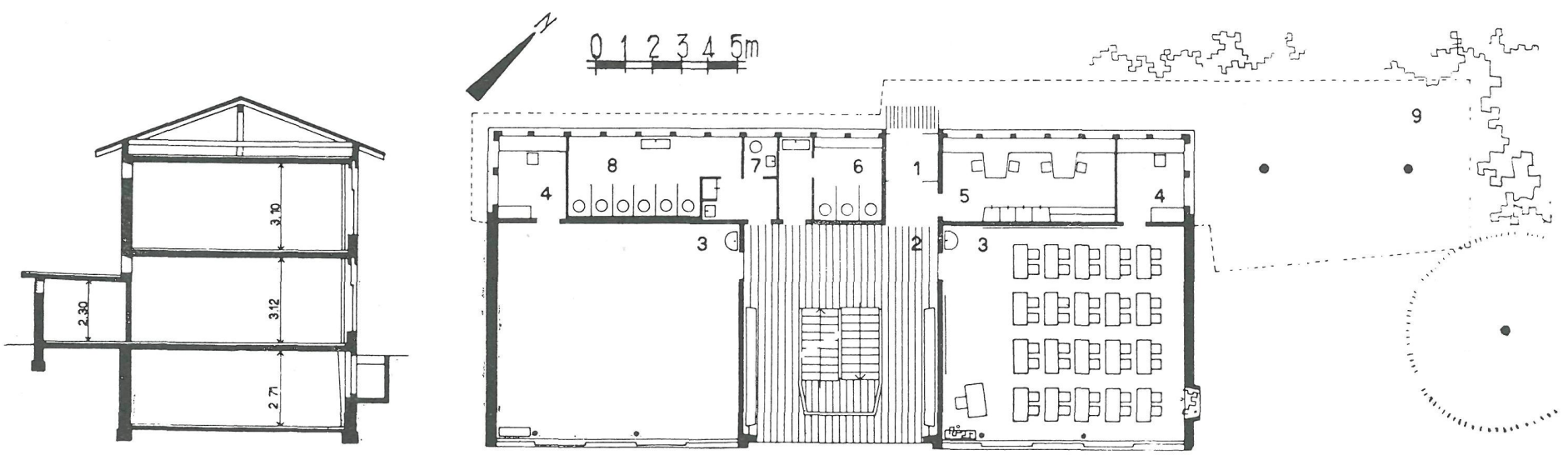

1. Entrada.-2. Guardarropas.-3. Clases: $8,7 \times 7,8$ m.-4. Almacén 5. Profesores.-6. Lavabos niños.-7. Lavabos profesores.-8. Lavabos niñas.-9. Campo de juego cubierto.

La iluminación de las clases se consigue por medio de grandes ventanales orientados a mediodía y huecos rasgados altos que dan al norte,

lo que supone una gran ventaja para la ventilación en épocas de calor.

El ancho de la escalera, de 1,35 m, es suficiente para absorber la circulación, incluso en los momentos de mayor tránsito.

El descansillo intermedio favorece la circulación.

La situación aislada de la escalera permite situar los guardarropas y aseos fuera de la zona de tráfico.

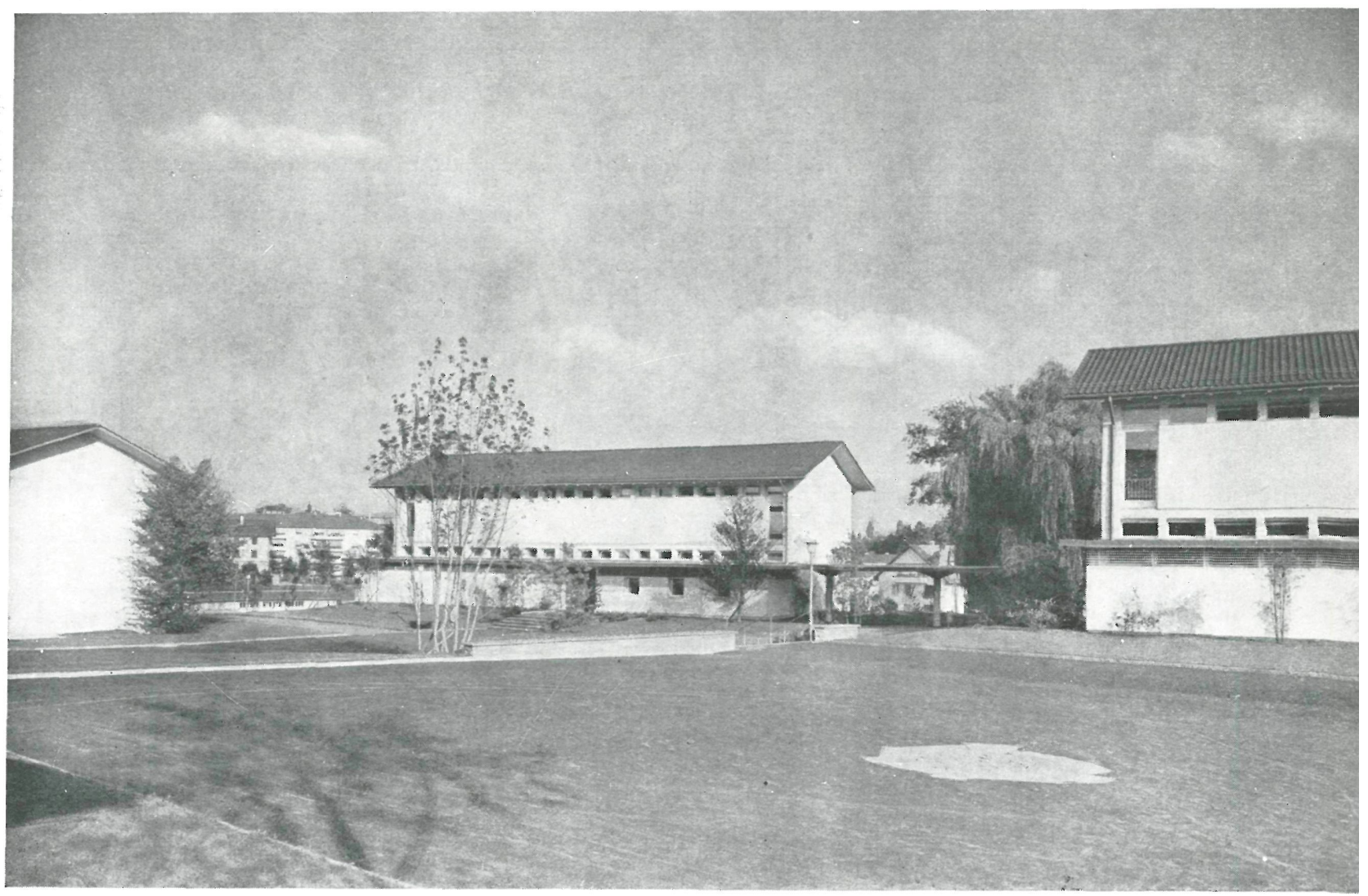




\section{g i m n a s i o}
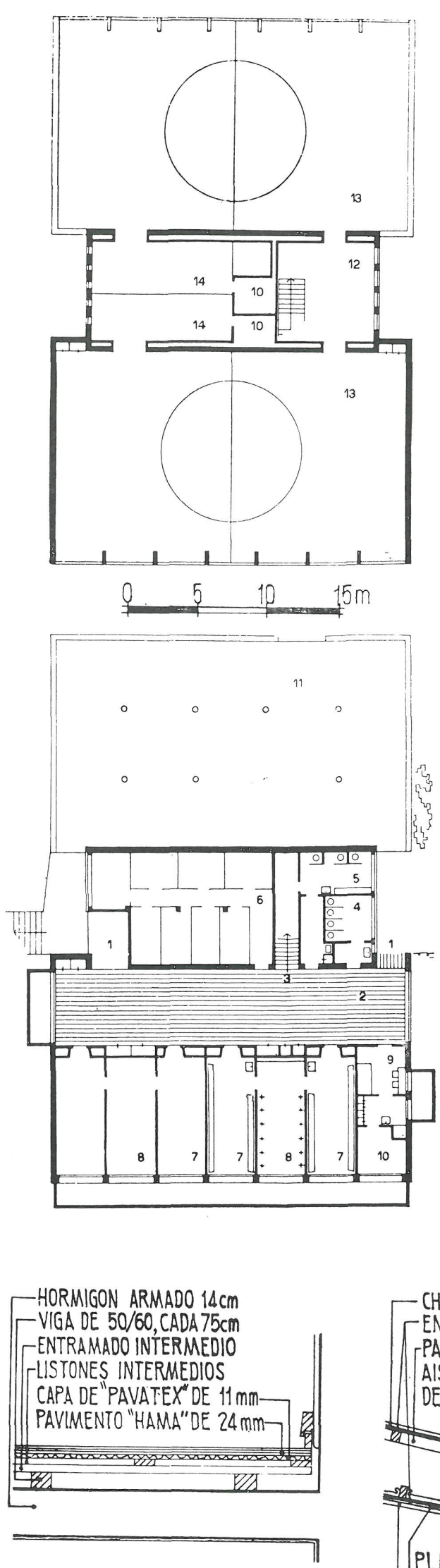

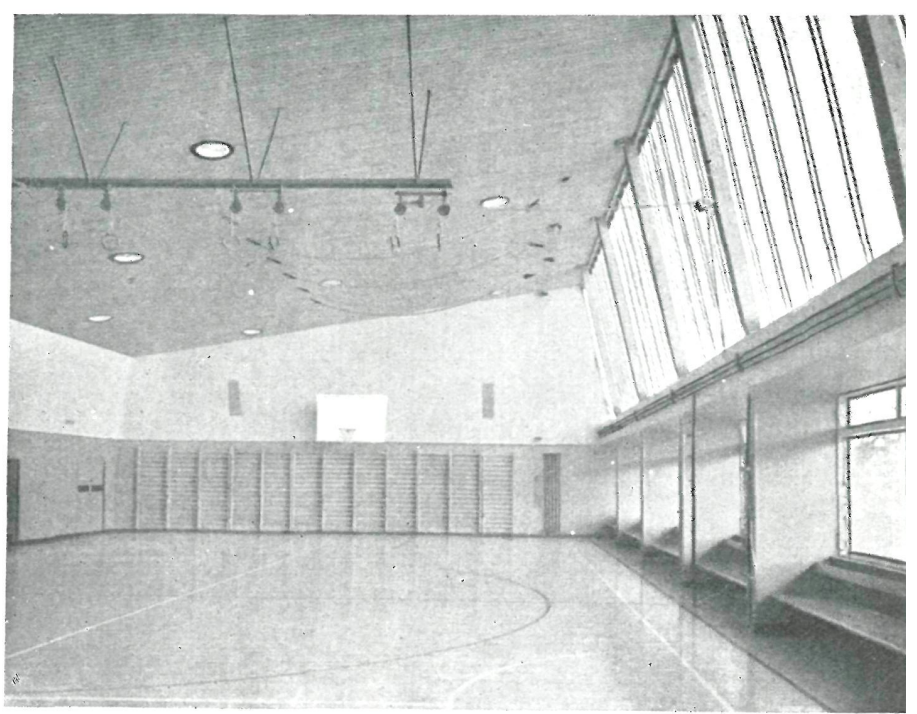

Las dos aulas de la planta baja disponen de un almacén propio, mientras que la de la planta superior sólo tiene un armario en la antesala. Todos los pabellones también disponen de dos almacenes y aula para trabajos manuales en el sótano, que pueden servir como refugio antiaéreo llegado el caso.

Estos pabellones tienen una personalidad propia tal, que son totalmente independientes entre sí y, por tanto, se ha considerado superflua toda comunicación cubierta entre los mismos. En cada uno existen: una pequeña sala de profesores, con su guardarropa correspondiente y aseos; un despacho para el director, y una sala de conferencias reducida.

El deseo de levantar los edificios con la menor altura posible para no perder la escala infantil escolar, y la tendencia de dar a las ventanas del gimnasio la orientación sur, condujo en este pabellón a adoptar una cubierta en diente de sierra, la cual, además de resolver favorablemente la iluminación, proporciona un ambiente acústico favorable.

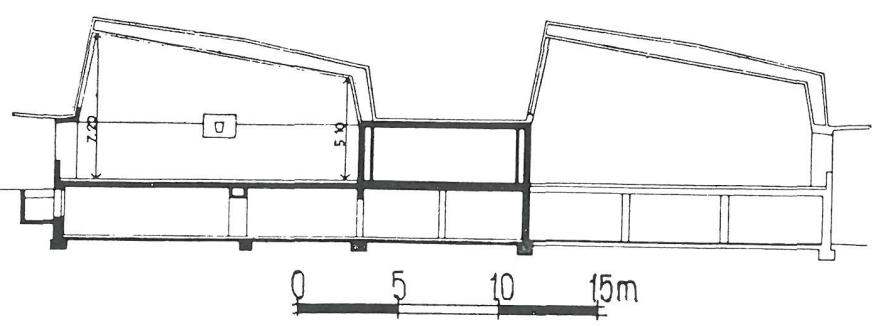

1. Entrada.-2. Sala.-3. Escalera.-4. Lavabos niñas.-5. Lavabos niños.-6. Equipo visitante.-7. Guardarropas.-8. Duchas.-9. Botiquín.-10. Ventilación.-11. Bicicletas.-12. Vestíbulo.-13. Gimnasio de $14,2 \times 25,0 \mathrm{~m}$.- 14 . Almacén utensilios. 

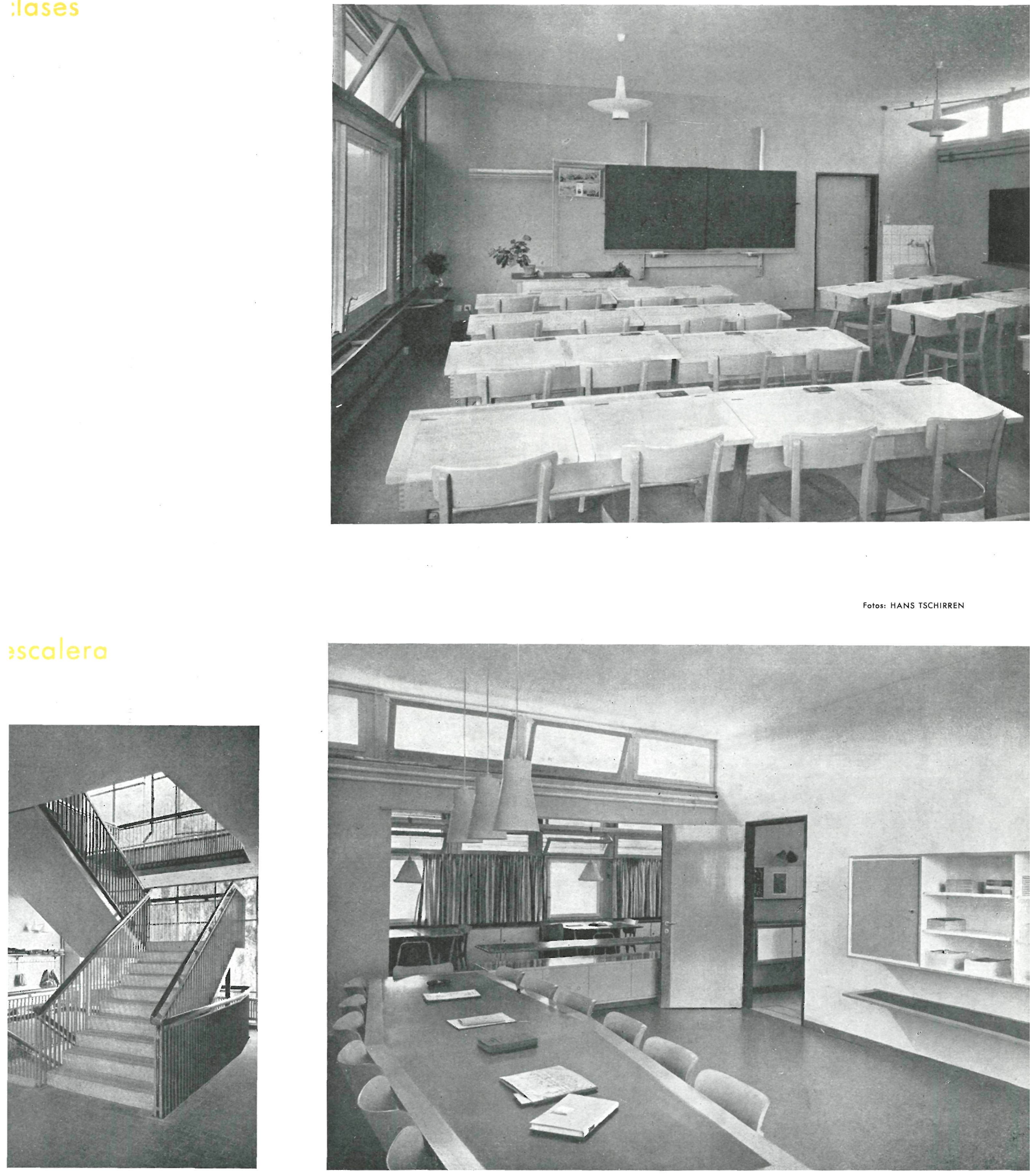

Fotos: HANS TSCHIRREN

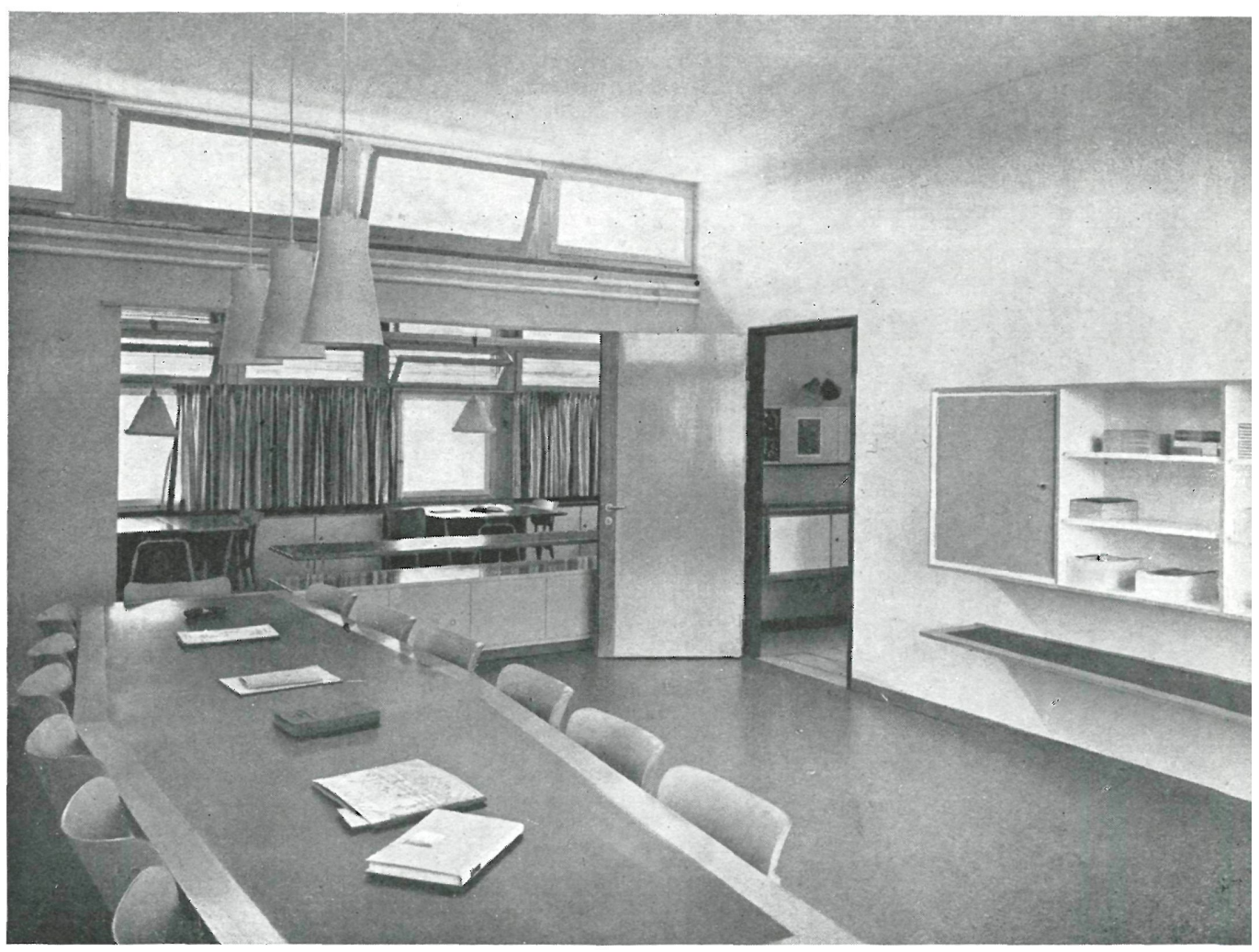

